\title{
Southern Roles in Global Nanotechnology Innovation: Perspectives from Thailand and Australia
}

\author{
Donald C. MACLURCAN ${ }^{\text {ai }}$ \\ a Institute for Nanoscale Technology, University of Technology Sydney
}

\begin{abstract}
The term 'nano-divide' has become a catch-phrase for describing various kinds of global nanotechnology inequities. However, there has been little in-depth exploration as to what the global nano-divide really means, and limited commentary on its early nature. Furthermore, the literature often presents countries from the Global South as 'passive' agents in global nanotechnology innovation without the ability to develop endogenous nanotechnology capabilities. Yet others point to nanotechnology providing opportunities for the South to play new roles in the global research and development process. In this paper I report on the findings of a qualitative study that involved the perspectives of 31 Thai and Australian key informants, from a broad range of fields. The study was supplemented by a survey of approximately 10 per cent of the Thai nanotechnology research community at the time. I first explore how the global nano-divide is understood and the implication of the divide's constructs in terms of the roles to be played by various countries in global nanotechnology innovation. I then explore the potential nature of Southern passivity and barriers and challenges facing Southern endogenous innovation as well as an in-depth consideration of the proposition that Southern countries could be 'active' agents in the nanotechnology process. I argue that it is the nano-divide relating to nanotechnology research and development capabilities that is considered fundamental to nanotechnology's Southern outcomes. The research suggests that Southern countries will encounter many of the traditional barriers to engaging with emerging technology as well as some new barriers relating to the nature of nanotechnology itself. Finally, the research suggests that nanotechnology may offer new opportunities for Southern countries to enter the global research and development picture.
\end{abstract}

Keywords. Nanotechnology; Global South; developing countries' innovation; Research and Development; Nano-divide; ethics

\section{Introduction}

The term 'nano-divide' has become a catch-phrase for describing various kinds of global nanotechnology inequities [See, for example, 1, 2-4]. Whilst common understandings appear to broadly relate to who will benefit from the fruits of nanotechnology innovation, there has been little in-depth exploration as to what the term 'nano-divide' really means. Moreover, despite early signs of surprisingly high levels of active Southern country engagement in nanotechnology [5, 6], little detail has

\footnotetext{
' Corresponding Author: PO Box 123 Broadway, NSW 2007, Australia; Email: donald.c.maclurcan@uts.edu.au.
} 
been garnered about how the nano-divide might play out. Questions remain, for example, about whether nanotechnology offers truly new challenges and opportunities for the South or whether the issues faced are generic and re-hashed. Or is the divide such a bad thing after all? Compounding these matters has been a significant lack of Southern input in international debates about the technology's trajectory [6].

In this paper I aim to provide clarity about what the 'nano-divide' actually means, and explore two propositions relating to the role of Southern countries in global nanotechnology innovation: that the South will be 'left behind'; and that nanotechnology provides opportunities for the South to play an active role in global innovation.

\section{Methods}

This paper reports on a 2004 qualitative study undertaken in Thailand and Australia ${ }^{\text {ii. }}$ A group of key informants ${ }^{\mathrm{iii}}$, sixteen from Thailand and fifteen from Australia, were interviewed about their understandings and perspectives relating to nanotechnology, as part of a wider study on nanotechnology and the South.

Whilst the study sought exploratory, rather than representative, perspectives on how nanotechnology might be understood in the South, a key informant process was used to ensure a range of perspectives were considered [9]. Given the argument that studies assessing nanotechnology's impacts relating to the South must go beyond consultations based purely on scientific perspectives [10], this study included interviewees with expertise in ethics, law, social science, science policy and development. Effort was made to ensure the involvement of people with experience across the 'development process', from grassroots activism through to government policymaking and industry leadership, with interviewees coming from academia, as well as private, government and non-government (NGO) sectors. Nineteen of the key informants $(61 \%)$ were engaged in work that involved nanotechnology. All key informants from Thailand were Thai citizens. Tables 1 and 2 outline each key informant's relevant position and affiliation, as of the time of their interview.

Key informants were identified through web and literature searches as well as a simplified process of co-nomination [11].

Linguistic, financial and temporal limitations, as well as nanotechnology's nascent stage at the time of the study, restricted the ability for wider public engagement, particularly outside of Bangkok, Thailand. Despite every effort to ensure diversity, the majority of Thai key informants spoke fluent English and had, at some stage, received

\footnotetext{
ii This paper shares its methodology with previous research I have published [7].

iii Key informants, or experts, are defined as "...those who can provide relevant input to the process, have the highest authority possible and are committed and interested" [8].
} 
educational training abroad. The results of this study must be interpreted with these limitations in mind.

Table 1. Thai Interviewees

\begin{tabular}{|c|c|c|}
\hline Name & Position, Affiliation & Sector \\
\hline Gothom Arya & Chairman, Appropriate Technology Association, Thailand & NGO \\
\hline Tanit Changthavorn & $\begin{array}{l}\text { Intellectual Property Specialist, National Centre for Genetic } \\
\text { Engineering and Biotechnology, National Science and } \\
\text { Technology Development Agency }\end{array}$ & Government \\
\hline $\begin{array}{l}\text { Tawatchai } \\
\text { Charinpanitkul }\end{array}$ & $\begin{array}{l}\text { Associate Dean for Research Affairs, Faculty of Engineering, } \\
\text { Chulalongkorn University }\end{array}$ & Academic \\
\hline $\begin{array}{l}\text { Suwabun } \\
\text { Chirachanchai }\end{array}$ & $\begin{array}{l}\text { Associate Professor, Petroleum and Petrochemical College, } \\
\text { Chulalongkorn University }\end{array}$ & Academic \\
\hline Nares Damrongchai & $\begin{array}{l}\text { Policy Researcher, Asia Pacific Economic Cooperation Centre } \\
\text { for Technology Foresight }\end{array}$ & Government \\
\hline Joydeep Dutta & $\begin{array}{l}\text { Associate Professor, Microelectronics, Asian Institute of } \\
\text { Technology }\end{array}$ & Academic \\
\hline $\begin{array}{l}\text { Worsak Kanok- } \\
\text { Nukulchai }\end{array}$ & $\begin{array}{l}\text { Professor, Structural Engineering, Asian Institute of } \\
\text { Technology }\end{array}$ & Academic \\
\hline $\begin{array}{l}\text { Promboon } \\
\text { Panitchpakdi }\end{array}$ & Director, Raks Thai Foundation & NGO \\
\hline Pakdee Pothisiri & Senior Deputy Permanent Secretary, Ministry of Public Health & Government \\
\hline Pinit Ratanakul & $\begin{array}{l}\text { Executive Director, College of Religious Studies, Mahidol } \\
\text { University }\end{array}$ & Academic \\
\hline $\begin{array}{l}\text { Pathom } \\
\text { Sawanpanyalert }\end{array}$ & $\begin{array}{l}\text { National Professional Officer (Health Systems Development), } \\
\text { World Health Organisation, Thailand }\end{array}$ & NGO \\
\hline Sirirurg Songsivilai & Chairman \& Co-Founder, Innova Biotechnology Co. Ltd & Private \\
\hline Nadda Sriyabhaya & President, Stop-Tuberculosis Association, Thailand & NGO \\
\hline $\begin{array}{l}\text { Wiwut } \\
\text { Tanthapanichakoon }\end{array}$ & $\begin{array}{l}\text { Director, National Nanotechnology Centre, National Science } \\
\text { and Technology Development Agency }\end{array}$ & Government \\
\hline $\begin{array}{l}\text { Pairash } \\
\text { Thajchayapong }\end{array}$ & Advisor to the Prime Minister on Science and Technology & Government \\
\hline $\begin{array}{l}\text { Yongyuth } \\
\text { Yuthavong }\end{array}$ & $\begin{array}{l}\text { Senior Researcher, National Centre for Genetic Engineering and } \\
\text { Biotechnology, National Science and Technology Development } \\
\text { Agency }\end{array}$ & Government \\
\hline
\end{tabular}

Table 2. Australian Interviewees

\begin{tabular}{lll}
\hline Name & Position, Affiliation & Sector \\
\hline Leigh Berwick & Investment Manager (Nanotechnology), Invest Australia & Government \\
\hline $\begin{array}{l}\text { Vijoleta Braach } \\
\text { Maksvytis }\end{array}$ & $\begin{array}{l}\text { General Manager, Global Aid, Commonwealth Scientific } \\
\text { Industrial Development Organisation }\end{array}$ & Government \\
\hline Paul Bryce & $\begin{array}{l}\text { Director, APACE-VFEG (Appropriate Technology for } \\
\text { Community and Environment Inc - Village First Electrification } \\
\text { Group) }\end{array}$ & NGO \\
\hline Melinda Cooper & $\begin{array}{l}\text { Research Fellow, Department of Sociology, Macquarie } \\
\text { University }\end{array}$ & Academic \\
\hline
\end{tabular}




\begin{tabular}{|c|c|c|}
\hline Bruce Cornell & Senior Vice President and Chief Scientist, AMBRI Pty Ltd & Private \\
\hline Patricia Coyle & $\begin{array}{l}\text { Medical Doctor, Department of Anaesthesia, Royal Prince } \\
\text { Alfred Hospital }\end{array}$ & Government \\
\hline Peter Deutschmann & $\begin{array}{l}\text { Director, Australian International Health Institute, University of } \\
\text { Melbourne }\end{array}$ & NGO \\
\hline Mike Ford & $\begin{array}{l}\text { Associate Director, Institute for Nanoscale Technology, } \\
\text { University of Technology, Sydney }\end{array}$ & Academic \\
\hline Mike Lynskey & Chief Executive Officer, The Fred Hollows Foundation & NGO \\
\hline Benno Radt & $\begin{array}{l}\text { Research Fellow, Department of Chemical and Biomolecular } \\
\text { Engineering, University of Melbourne }\end{array}$ & Academic \\
\hline Michael Selgelid & $\begin{array}{l}\text { Sesqui Lecturer in Bioethics, Faculty of Medicine, University } \\
\text { of Sydney }\end{array}$ & Academic \\
\hline Greg Tegart & $\begin{array}{l}\text { Executive Advisor, Asia Pacific Economic Cooperation Centre } \\
\text { for Technology Foresight }\end{array}$ & Government \\
\hline Chris Warris & Researcher, Australian Academy of Science & $\mathrm{NGO}$ \\
\hline Terry Turney & $\begin{array}{l}\text { Director, Nanotechnology Centre, Commonwealth Scientific } \\
\text { Industrial Development Organisation }\end{array}$ & Government \\
\hline John Weckert & $\begin{array}{l}\text { Professor, Centre for Applied Philosophy and Public Ethics, } \\
\text { Charles Sturt University Wagga }\end{array}$ & Academic \\
\hline
\end{tabular}

The study was supplemented by a two-page, mailed survey to members of the Thai nanotechnology research community. Members of this community were identified through available literature, particularly via leads arising from the 2004 document: "Final Report: Survey for Current Situation of Nanotechnology Researchers and R\&D in Thailand", published by researchers at Chulalongkorn University [12]. The survey received a high return rate, with participants constituting approximately 10 percent of the Thai nanotechnology research community at the time ${ }^{\text {iv }}$.

A study of a small number of key informants and nanotechnology practitioners in Thailand can in no way be seen as indicative of attitudes across the non-homogenous South, particularly given Thailand's lack of a colonial history. However, Thai perspectives can be useful for exploring and considering nanotechnology and the South, given the situation Thailand faces in terms of both development and nanotechnology.

Thailand is classified by the United Nations Development Program as a "middle income country" [13] and is ranked 74th out of 175 countries on the Human Development Index ${ }^{\mathrm{v}}$ [14]. In recent decades it has experienced remarkable progress in human development [13]. However, Thailand's greater population continues to face significant challenges. As of $2004,21 \%$ of the Thai population earned less than $\$ 2$ a

\footnotetext{
${ }^{\text {iv }}$ This figure is estimated, based on a previous report's claim that the overall number of nanotechnology practitioners in Thailand was around 100 [12].

${ }^{v}$ An index combining normalized measures of life expectancy, literacy, educational attainment, and GDP per capita for countries worldwide.
} 
day [15], whilst financial inequality had increased over the past 40 years, particularly between urban and rural areas [13]. Stark inequities are also evident in the distributed burden of the HIV/AIDS epidemic and general access to health services [13]. Various populations still suffer from very high levels of child malnutrition and maternal mortality, whilst overuse of pesticides is a threat to many in rural areas [13]. Despite the fact that the vast majority of Thais live in rural locations, the country is experiencing rapid urbanisation as well as an ageing population [14].

In terms of it engagement with emerging technology, Thailand has supportive infrastructure and strong hopes for biotechnology R\&D [16]. In an early study of Southern nanotechnology capabilities, Thailand was identified as a "middle ground" Southern country [5]. This analysis is supported by early evidence of nanotechnology R\&D [12, 17-20], including the establishment of a national centre [21] and development of a national nanotechnology strategy [22]. Just as Thailand faces significant challenges with biotechnology innovation [18], so too do people claim Thailand faces significant challenges for nanotechnology innovation [19, 23]. From the perspective of ELSI, Thailand has a history of controversy in biotechnology, ranging from issues of morality [24] and environmental concerns [25], through to issues of intellectual property such as 'biopiracy' [26, 27] and compulsory licensing [28]. Yet already, the ELSI of Thai nanotechnology has created controversy around the issue of 'atomically modified organisms' [29].

Given the role of the North in shaping and driving debates about nanotechnology and the South, the value of simultaneously considering Northern perspectives must not be underestimated. Australian perspectives can act as a useful reference point given the country has been firmly entrenched in international nanotechnology debates having developed the world's first 'nanomachine' in 1997 [30]. However, as of 2004, Australia also lacked a formal national nanotechnology initiative and its global output was below expected levels [31]. Furthermore, Australia has also faced a slow uptake of engagement with ELSI debates in areas such as health and safety [32], and low levels of public understanding and knowledge about nanotechnology [33].

Considering the importance of the interviewee's own framework of meanings, the 31 interviews were semi-structured, which allows for a broad framing but individual divergence [34]. Each interview lasted between 20 and 80 minutes, was face-to-face ${ }^{\mathrm{vi}}$, and interviewees were offered professional translation services. All data was analysed using $\mathrm{NVivo}^{\mathrm{TM}}$ software, noted for its ability to assist in developing an emergent analysis [36].

\footnotetext{
${ }^{\text {vi }}$ Noted as an advantageous method in future-oriented research [35].
} 


\section{Results}

In section 2.1 I explore how the nano-divide is understood and the implication of the divide's constructs in terms of the roles to be played by various countries in global nanotechnology innovation.

The literature often presents Southern countries as 'passive' agents in global nanotechnology innovation - with an inability to develop endogenous nanotechnology capabilities. In section 2.2 I explore the nature of that passivity and barriers and challenges facing Southern endogenous innovation.

Others in the literature point to nanotechnology providing opportunities for the South to play new roles in the global R\&D process. In section 2.3 I entertain the proposition of Southern countries as 'active' agents in the nanotechnology process.

\subsection{Understanding the Nano-Divide and its Constructs}

Interviewees regularly referred to the term 'nano-divide' but assumed its meaning and knowledge of how it is constructed are commonly understood. Given the apparent difference in understandings that emerged, in this section I seek to piece together interviewee comments to establish some relevant clarity. The first part considers how the term 'nano-divide' is interpreted and understood. The second explores some early characteristics of the nanotechnology innovation divide in terms of its leaders and those 'left behind'. Addressing these two points establishes a context and framework for my assessment, in this paper, of Southern roles in the global nanotechnology innovation.

Generally speaking, the literature does not clarify what is meant by a 'nanodivide'. Yet it is clear that, for interviewees, the term 'nano-divide' can have two different meanings. The first, that I term the 'nano-innovation divide', refers to inequity based on where knowledge is generated and retained and a country's capacity to engage in these two processes. Tegart presented this divide as one between the "information rich and information poor..." [37]. Those on the 'leading' side of this divide are seen as able to actively contribute to and direct nanotechnology's trajectory, whilst those who are 'left behind' are seen as playing passive roles, unable to exert influence over any sphere of nanotechnology's global trajectory. The second meaning, that I term the 'nano-orientation divide', refers to inequity based on the areas in which nanotechnology research is targeted, as compared to the areas in which it would address basic human needs. In this sense, Arya spoke of a differentiation between nanotechnology addressing 'real' and 'felt' needs [38]. For many, this translated into a belief that nanotechnology would be governed more by market push- rather than social pull-factors.

Whilst the divides differ in their nature, where research is targeted is often initially dependent on where knowledge is being generated and retained. Given that most of the world's research into emerging technology occurs in the North, comments on the orientation divide generally related to global inequities in terms of limited Northern research focused on Southern problems. However, the prospect of the South as active 
agents in global nanotechnology innovation prompts additional consideration for inequities in the orientation of Southern generated knowledge - a matter I will explore in a future paper.

According to the interviewees, there is an increasing concentration of nanotechnology R\&D generation and ownership in the hands of "limited leading countries" [39]. These countries were classified as 'leaders' largely because of the high levels of early nanotechnology investment $[37,40,41]$ and also happened to be some of the more wealthy countries in the world [42]. Leaders in nanotechnology innovation were said to include ${ }^{\text {vii }}$ the U.S., Japan, Taiwan, Germany, Australia, Sweden, the U.K., France, Switzerland and Hong Kong ${ }^{\text {viii }}$.

Given certain countries are leaders of nanotechnology innovation, it stands to reason that certain countries be 'left behind' [43-47]. The previously outlined pressure to be at the forefront of nanotechnology innovation is often driven by a belief that if a country neglects nanotechnology it will be in an unenviable position later on [47, 48], having to try to "catch-up" [46]. According to Tanthapanichakoon, even a country with endogenous nanotechnology capabilities could fall behind if it did not seek to constantly develop its research position [47]. The insinuation here is that, rather than all countries gaining from nanotechnology, no matter what the nature of their engagement, those that do not develop and maintain competitive innovative capabilities will actually lose out. Furthermore, as shall be explored in section 2.2, there is a perceived potential for nanotechnology to actually reinforce the underdevelopment of some countries by creating greater technological dependency [38, 41, 49].

The proposition that countries will play different 'roles' in global nanotechnology innovation prompts a greater exploration of exactly what kind of roles are envisaged for the South. Will the South be left behind by nanotechnology or will the situation present new opportunities allowing Southern countries to become agents in global nanotechnology innovation? As shall be seen in sections 2.2 and 2.3, this question leads to an exploration of the barriers and possibilities for Southern nanotechnology innovation.

Four key issues relating to barriers and possibilities were presented as largely determining Southern roles in global nanotechnology innovation, these being "their understanding, their commitment, the resources and infrastructure" [43]. Whilst many perspectives, particularly Australian, went beyond considering the development 'problem' as one solely influenced by issues of domestic Southern capacity by also looking at global externalities and contexts, these four issues form the crux of my discussion in this paper.

\subsection{The South Left Behind}

\footnotetext{
vii In descending order of interviewee level of citation.

viii China was not considered a nanotechnology 'leader', although its grouping with the North, in terms of nanotechnology prowess, will be discussed later.
} 
Interviewees presented a number of different explanations for why Southern countries might be left behind in nanotechnology's global development. In the first part of this section I look at some of the envisaged scenarios, exploring varying levels of engagement and different kinds of roles. I then progresses to addressing the underlying assumption - that the South cannot play an active role in global nanotechnology innovation - by exploring the perceived challenges to developing innovative capabilities.

For some Australian interviewees, the possibility for nanotechnology's development in the South was either non-existent, a "contradiction in terms" [50] or "[not] a direct link, by any means" [51]. Those who struggled to see any link suggested that nanotechnology was irrelevant to the South and that not only was endogenous R\&D unlikely, but that they may not even play the role of 'recipient', given that “...existing, basic, often very cheap, sometimes even free, technologies or medicines, are not available in developing countries..." [52].

However, many of the interviewees, led by the Australians, saw the link between nanotechnology and the South via some form of passive diffusion, where the role of the South was as 'recipient', rather than innovator, particularly in the "very, very poor countries in Africa" [37]. The common implication was that nanotechnology will most likely reach the South as a result of Northern influence. Selgelid's response highlighted this mindset when he commented, "nanotechnology would be great if someone really made it and provided it to developing countries" [52]. Bryce's reasoning was along similar lines as he saw diffusion coming via a "serendipitous process" [53].

Northern-dictated aid was seen as likely mechanism for Southern engagement with nanotechnology. Berwick, a policy officer with Invest Australia, saw potential for nanotechnology to be incorporated in "world aid programs and assistance programs to help developing nations just help themselves develop further" [46]. Similarly, Cornell referred to potential areas of application in U.N. aid packages or U.S. or European initiatives operating in the South [51]. Australian interviewees also saw the potential for international aid organisations to invest in Southern nanotechnology, commonly citing organisations such as the Bill and Melinda Gates Foundation. Braach-Myksvitis noted that this kind of activity has already commenced, with the Global Research Alliance ${ }^{\mathrm{ix}}$ having been approached by a number of Northern foundations wishing to ensure the benefits of nanotechnology reach the South in this way [54]. Damrongchai, a Thai technology policy officer, agreed that there was potential for nanotechnology to enter the South via aid, citing potential applications such as single-life diagnostic kits, and methods by which to increase food preservation [39]. Damrongchai's comments were distinct, with most Thai interviewees ambivalent about nanotechnology's potential delivery through aid and development assistance, having given little consideration to the idea. Panitchpakdi was one who spoke about the potential for

${ }^{\text {ix }}$ An alliance of nine knowledge-intensive technology organisations from around the world (www.research-alliance.net). 
greater Southern dependency as a result of becoming recipients of nanotechnologybased aid whereby it would "... all depend on the countries that are advanced [if they] are willing to share" [55]. For Damrongchai, the idea of a Northern-controlled situation raised considerable concerns about donors exerting political influence and impressing conditionality upon Southern recipient countries [39].

As an extension of aid, technology transfer was also discussed as a mechanism by which the South's role would remain passive ${ }^{\mathrm{x}}$. Some interviewees suggested that, with the right education and training, nanotechnology could be transposed from the North to the South $[37,53]$. Importing products and technologies was viewed as a possible means of engagement for those countries without nanotechnology R\&D capabilities [38]. Kanok-Nuckulchai believed that less developed countries, although unable to "build technology themselves" even if they commence nanotechnology activities now, can still start accumulating the knowledge and, once they have sufficient human resources and infrastructure, “...can absorb and transfer some of technology..." [44].

Others saw this form of technology as entrenching the passivity of the South in global nanotechnology processes via a continuation of Southern technological dependency [56]. Some interviewees envisaged this dependency in terms of a 'trickledown' of nanotechnology from the North to countries without endogenous innovative capabilities [57]. Cornell, for example, imagined the South would only benefit "as a consequence" of 'spin-offs' from Northern nanotechnology advances in areas such as water desalination, cheap nutritional foods and low cost fuels [51]. Weckert was similarly cynical about the way in which many Southern countries would engage with nanotechnology, suggesting that until developing countries "...get a bit more economically advanced", their engagement may be limited to Northern companies who "see some big economic advantage" of distributing nanotechnology in the South [58]. Tegart added that a number of U.S. companies might already be viewing the South as a "potential market" for Northern products [37]. In this respect, a number of Thai interviewees confirmed that 'nano-products' have already entered the Thai market [39, 59]. What emerged in the interviews was a strong fear of 'import dependency', with some saying that Thailand could end up "...buying a lot of things" [49] and "losing a lot of currency' by buying-in high-cost technology through both products and services $[44,49]$. Furthermore, Thai interviewees constantly referred to an "import threat" [41], with one practitioner worried about a flood of "cheap products from China" and Charinpanitkul adding that the danger lies in imported nanotechnology products entering the Thai market and the population ignoring domestically-produced products once they "...get[s] used to those [international] products" [41]. For Damrongchai, it is this continual buying of products from the North that perpetuates underdevelopment [39].

${ }^{\mathrm{x}}$ The role of licensing will be explored in a future paper as a strategy for developing endogenous innovation capabilities. 
Another kind of passive role presented the South as 'nano-manufacturers'. Thai interviewees saw a role for the South to "partner in the manufacturing stage" with Northern counterparts [43]. Weckert suggested this was merely the outsourcing of work by companies in the North [58]. Dutta saw the move to outsourced nanomanufacturing that would occur in Southern countries as a natural progression, explaining:

for niche products, [where the] investments are lower, they [developed countries] will have to transfer the technology where you need more labour, where you need larger space to manufacture. You cannot keep it in developed nations, it is too expensive... [60].

Others agreed it likely that countries with strong nanotechnology programs would exploit countries playing passive roles in its development [37, 61]. There was recognition that Northern nanotechnology R\&D partnerships with the South would seek to benefit from reduced costs [53] and lower levels of regulation in the South [51]. Ratanakul was sceptical that such partnerships would allow Southern countries to play an active role in global nanotechnology innovation, saying:

The problem is these Western scientists are doing research for their own benefit... When they finish the[ir] research they go back and then they create new technology, based on the research, and they sell it [to] us [57].

The suggestion here is that the North will value-add to nanotechnology products (possibly manufactured in the South) and that those not absorbed by Northern markets or considered 'too risky', will be off-loaded to the South, as often happens with pharmaceuticals. In this light, Deutchmann spoke of his concern that "....junk products would be dumped at a cheap price on the developing world..." [40], with Cornell believing that many developing countries will take "...whatever is available at a reasonable price" [51].

At the heart of nearly all of these scenarios is the assumption that nanotechnology R\&D, and therefore a potentially active role in global nanotechnology innovation, is limited to the developed countries and beyond the realm of developing countries. Turney and Berwick respectively spoke of a "cultural perception" and "natural tendency" to expect that nanotechnology will be a 'developed world technology' [46, 48]. Interviewees such as Chirachanchai provided support for this hypothesis by speaking of the "advanced countries" assuming leadership roles in global nanotechnology innovation [59]. Additionally, there was a belief that "developing countries are going to miss the boat... [and not take] advantage of nanotechnology to exploit their local, competitive advantages..." [48]. Dutta said that if Southern nanotechnology is to face barriers they will be barriers of Northern perception, commenting: "...some of the people may think 'what the hell can you do in nanotechnology in Thailand"' [60]. But there was also evidence of domestic challenges relating to Southern perceptions. Kanok-Nukulchai, amongst others, noted that his initial impressions about developing nanotechnology in a country such as Thailand were "distant", with ventures into research feeling "contradictory" [42]. Others spoke 
of the barrier of internal cynicism. They suggested that even in a country making efforts to become active in global nanotechnology innovation, there is potential for people to think "it is just too difficult..." [48], or that the research is "too late" to catch the North, leading to the cessation of activity [59].

Driving these perceptions was a belief that "in-house" development of nanotechnology is too difficult for many Southern countries, given the weak capacity for innovation [49]. A range of factors were presented as challenges to developing capacity, commencing with issues of Southern nanotechnology awareness and commitment, moving to issues of basic capacity through to challenges in growing and maintaining competitive R\&D capabilities. In explaining the challenges to Southern countries playing active roles in global nanotechnology innovation, Thai interviewees often used examples from the Thai experience.

Preceding the issue of basic capacity was a belief that a lack of awareness, understanding and commitment could inhibit the ability for Southern countries to enter global nanotechnology innovation. In this light, a number of Australian interviewees said that the initial barriers to Southern innovation include awareness of what nanotechnology is actually about [61] and recognition of its opportunities and future importance $[37,45]$. This lack of awareness was compounded by poor understanding, particularly amongst Southern leaders, that Tegart saw as a major challenge for the South [37]. In contrast, Thajchayapong suggested that there is a great deal of public awareness around nanotechnology and a general acceptance of nanotechnology's merits amongst policymakers in the E.U., Japan and the U.S. [62].

According to many interviewees, lack of awareness and understanding about nanotechnology fits within a bigger picture in the South where nanotechnology innovation is 'prioritised out' by more immediate needs [48] to do with the "basic requirements of life" [51]. In this respect, Kanok-Nukulchai explained that nanotechnology is perceived as a "luxurious" investment, particularly in light of its embryonic state of development and the long-term nature of 'returns' [42].

Following on from this, some interviewees saw a challenge for the South in gaining political commitment for nanotechnology [37, 55]. This could translate to inadequate resource allocation [37,63], with a particular concern that Southern nanotechnology R\&D would be under-funded $[37,45,55,60,63,64]$. As Tanthapanichakoon noted about the Thai situation, “...we still do not have a very strong budget or input into nanotechnology" [47]. This perspective was supported by a number of Thai nanotechnology practitioners who claimed low budgets were inhibiting the progress of their work.

In addition to awareness, understanding and commitment, “...so many other challenges" were seen as reducing the ability to develop nanotechnology capabilities [65]. As Warris noted, "...[developing countries] have got to get certain things in order before they can get into more high-tech applications, such as nanotechnology" [45]. In this light, interviewees pointed to challenges with respect to both basic knowledge and capacity. 
In terms of basic knowledge, there was a belief that Thailand lacks the fundamental knowledge to engage in nanotechnology [43]. Chirachanchai elaborated by saying that, in the past, "understanding at the molecular level has been neglected" [59]. According to others, the fact that "the science is not quite there" [62] was believed to place the country "a bit far behind from the very beginning" [59]. More generally, Cornell was sceptical about the ability for developing countries to lead innovation, saying: "the idea of them being at the frontier of any of these areas is somewhat difficult to perceive, given the fact that it is born, really, at the very cuttingedge of developed country science..." [51].

With respect to basic capacity, interviewees specifically referred to 'human resources' as the "biggest concern" [39] and the "greatest obstacle" [41] to Southern nanotechnology innovation. In this respect, Thailand was already said to be experiencing a shortfall of researchers [44, 49, 60], compacted by the belief that Thailand will face difficulties in finding people with an 'interest' in nanotechnology $[38,63]$. But Lynskey suggested that this lack of a "critical mass" of relevant human resources actually means that the idea of a country such as Eritrea developing endogenous nanotechnology capabilities is "completely unrealistic" [65]. These challenges were placed in the broader context of a general shortage of science and technology researchers in the South ${ }^{x i}$ [47] and critical weaknesses in terms of educational capacity [37]. Cornell said that this will be a particular barrier for Southern nanotechnology, given the lack of "long-standing commitment to education" in areas such as the molecular sciences that form the basis for developing nanotechnology capabilities [51]. On the other hand, strong levels of human resources were seen as the backbone to nanotechnology innovation in a number of Northern countries such as Japan and Taiwan [42, 62].

Yet there was a belief that shortfalls in the specific kind of human resources required to drive nanotechnology innovation will mean even greater challenges for the South [64]. Dutta spoke of particular Thai shortfalls with respect to those with basic knowledge in quantum physics and chemistry, or those with an ability to shift into nanotechnology from other fields [60]. For Turney, this was part of a general problem in terms of the "level of education" of current or potential practitioners within the South [48]. In addition to researchers, technicians were seen to be "critical people... in the exploitation of much of this technology" and a further area in which the South was viewed as being in a much weaker position than the North [37]. Kanok-Nukulchai noted that it may take some time to cultivate the expertise nanotechnology demands [42].

Furthermore, interviewees spoke of a strong potential for Southern nanotechnology researchers to be drawn to the North via the commonly expressed 'brain-drain' phenomena $[37,61]$. Brain drain was seen as a threat to retaining workers in a country such as Thailand if it did not have enough nanotechnology infrastructure and facilities,

xi 2.7 per 10,000 population in Thailand (according to Tanthapanichakoon). 
with a belief that the "best brains" would start to look to Singapore, the U.S. or Europe [39]. Others, including several Thai nanotechnology practitioners, saw this as part of the bigger challenge of creating a 'research culture' and general support for Thailand's scientific community. These challenges were seen as presenting a significant barrier to developing and retaining a critical mass of researchers in the South [37, 39, 61]. Ratanakul believed this was already a major challenge for Thailand, stating that “...the government has not been thinking of the measures to prevent the well trained Thai scientists from being lured away by affluent nations... [57].

The other threat posed by brain drain relates to the challenges of re-integrating returned researchers into Southern contexts. Charipanikul believed that it would be quite difficult for Thais with nanotechnology expertise to find employment upon return from overseas work or training [41]. Dutta explained that whilst "...the Thai government has spent a lot of funds to train people abroad..." their adaptation time upon return is too long "... because there are no active groups working here"[60].

In addition to human resources, many saw infrastructure as a basic requirement, and thereby major challenge, for the Southern development of nanotechnology capabilities. Interviewees first discussed problems with the amount of infrastructure available, referring only to 'hard' infrastructure in terms of equipment and instrumentation. Like a number of others, Dutta believed that “...nanotechnology needs quite a bit of infrastructure", given the scale on which the research occurs [60]. But Cornell noted more strongly that if a country wants to seriously engage in nanotechnology $R \& D$ then "you could fill telephone books with the kind of infrastructure that you need" [51]. In elaborating, Cornell outlined the need for:

an ability to work with ceramics, with plastics, organic chemistry development, with fine metals, thin-film deposition, you must have electronic foundries... you need everything that currently supports a modern industrial economy and that goes from screen-printing, paints, chemistries, lubricants, polymers, waxes, solvents, all of the moulding industries, the etching industries, electrochemical industries, [51].

In this respect, interviewees referred to the "limited capabilities" within the South [37, 47]. According to Cornell, developing countries have "...not yet advanced to the point whereby this kind of equipment, this kind of capability, is naturally part of their world" [51]. For Cornell, this was partially explained by the common, developing country absence of a military industrial complex that he saw as the foundation for driving innovation; pointing to the case of the U.S. where he saw nanotechnology driven in this manner [51].

The second aspect of infrastructure requirements relates to the quality and cost of instrumentation. Practitioners specifically mentioned the essential need for observation and characterisation instrumentation such as Tunnelling Electron Microscopes and thin-film coaters. In this respect, Thailand was seen to lack some of the required equipment [60], with Kanok-Nukulchai noting a perception that the technology is too advanced: 
...when we talk about nanotechnology most people think... it is something we cannot see, something that need[s] a lot of high-tech equipment and when we look back at Thailand we are not that advanced in terms of technology [42].

Prohibitive costs were presented as the main barrier to the acquisition of such instrumentation [46], with Cornell believing that nanotechnology requires "a fairly large investment in fairly expensive equipment" [51].

In addition to challenges with respect to basic capabilities, interviewees spoke of challenges relating to the development and maintenance of competitive, nanotechnology R\&D capabilities. There was a strong belief, for example, that access to appropriate instrumentation was a key barrier to the development of Southern nanotechnology strength. Radt believed many of the developing countries actually have the instruments required to undertake nanotechnology $R \& D$ but saw the barrier more as a matter of access to, and maintenance of, these instruments [64]. Dutta partly agreed, saying of the existing instrumentation, much of it is "underused" [60].

The challenges around developing basic nanotechnology capabilities suggest coordination and strategic planning is required. However, coordination is another area in which interviewees saw challenges for Thailand, with a genuine concern that research will be "unfocused and resource[s] will be scattered" [42]. Chirachanchai, for example, saw problems in ensuring that each research effort was part of an overall strategy for Thai nanotechnology [59]. In this light, Tanthapanichakoon highlighted that Thailand "...does not have a national strategy and all the labs, or centres, are working on their own interests or on their own subjects, without coordination..." [47]. Furthermore, Tanthapanichakoon said that Thailand suffers from a significant breakdown in communication between many of the government agencies that would need to be working together when it comes to nanotechnology innovation [47].

Accompanying coordination of research is the Southern challenge of strategic planning. Tegart believed the initial planning difficulty is in assessing capabilities and then selecting focused areas for research [37]. Dutta's concern, that people talk generally about nanotechnology without a concentrated focus in any particular direction [60], was seen as part of a bigger fear that Thai nanotechnology lacks a clear and comprehensive vision for the future [59].

But, developing focused nanotechnology research can be made more difficult if the ability to develop knowledge is restricted by nanotechnology innovation's global leaders. Interviewees strongly argued that some of the greatest barriers to Southern innovation relate to "who's involved and actually creating the technologies" [56] and, stemming from this, the "big issue" [39] of control over intellectual property rights.

Concerns about the inhibitive impact of Northern nanotechnology patenting upon Southern attempts to develop innovative capabilities were seen to be uniquely enhanced given nanotechnology relates to the fundamental building blocks of all material things [39]. Added to this, the potential disappearance of the 'cost-barrier' for nanotechnology R\&D (as shall be discussed in section 2.3), makes the issue of patent control "extremely important" because "...the powerbroker will be the knowledge" 
[54]. Furthermore, a major concern held by interviewees was that a great deal of nanotechnology patenting would be speculative in order to claim future applications. Pothsiri was worried that "a Western country, particularly in the private sector... may try to play around with this kind of thing without making any attempt to find a new innovation" [66]. Additionally, a number of interviewees said their concerns lay with the increasing move towards, or ambiguous nature of, "process" patents ${ }^{\mathrm{xii}}$ in light of a greater research focus on atomic self-assembly [52, 68]. In these respects, nanotechnology was seen as leading to corporate monopolies [57], locking up research in the North and thereby providing "....another key barrier to developing country uptake" [54] by blocking potential avenues for Southern R\&D [56].

One Thai interviewee spoke very strongly about how nanotechnology patenting will maintain and promote the technological divide through ongoing oppression of the South. Arya presented intellectual property rights as the "new economic power... [and] new instrument of domination", with patent holders often over-exploiting their position of strength [38]. He went on to say that the control of proprietary knowledge is driving greater oppression through a divide that, in addition to being technological, includes an:

...economic, social and also political divide, because those who have the new technologies will also invest, not only for the products to serve mankind but the products which can be used for domination, for hegemony, weapons of new kinds and so on and so forth [38].

General concerns were also held for the ability for Southern countries to translate nanotechnology research into patented knowledge. Charinpanitkul said that nanotechnology patenting in Thailand "...will be a big obstacle" given patent understanding, even in the university, is insufficient [41]. Added to this, Changthavorn pointed specifically to a lack of nanotechnology understanding amongst Thai lawyers [68]. Charinpanitkul saw the lack of knowledge as severe and inhibitive, highlighting, with respect to nanotechnology patent applications, “...we do not know even what style or what wording we should add..." [41].

A contributing factor to weak Southern patenting and another major challenge to the South playing active roles in global nanotechnology innovation is the potentially poor level of private sector engagement with nanotechnology R\&D [48]. Thajchayapong said that the science of nanotechnology actually demands greater participation from industry [62], with private sector participation suggested to be a crucial driver of early nanotechnology success in Japan and Taiwan [41].

Aside from foreseeable financial 'return', available financing and other financial incentives were seen as the initial drivers of private sector engagement in nanotechnology. However, building on earlier concerns about a general lack of

xii "A claim or claims to a process for the manufacture of a product, which may itself be the subject of a patent though it does not necessarily have to be" [67]. 
funding, there was a belief that risks, particularly those associated with intellectual property, could make access to nanotechnology finance and capital a serious problem in some of the Southern countries [48]. In this light, many saw the countries of the North in comparatively strong positions. Tanthapanichakoon, for example, suggested that a country such as the U.S. is in "the best position" when it comes to nanotechnology R\&D largely because of the "good system of venture capital" in place [47].

A second challenge facing the development of Southern-owned proprietary knowledge is the difficulty of technology transfer from academia to industry. The initial problem is that in a country such as Thailand a great deal of the nanotechnology research is 'fundamental' rather than 'applied'. As Tegart noted, whilst there are some Thai researchers completing PhD's in nanotechnology "they are rather pure science topics... and not very focused on practical and applied areas...." [37]. Secondly, Thai nanotechnology practitioner responses demonstrated weak professional links between academia and industry. Thajyapong said these weak links were most visible in the poor levels of communication about nanotechnology between industry, government policymakers, researchers and academia [62]. Finally, there was a belief that Southern firms are limited in their ability to absorb nanotechnology R\&D from academia [66].

Even leveraging from international partnerships to overcome capacity issues encountered skepticism. Interviewees highlighted barriers in terms of the lack of Southern infrastructure [51] and massive amounts of competition to be "at the forefront" in nanotechnology [42]. To elaborate, Tanthapanichakoon used the example of the New Energy and Industrial Technology Development Organisation of Japan whose policy, in terms of collaborative research, is "...no grants at all in nanotechnology field[s]" [47].

It is important to note that most of the challenges raised for the South to play an active role in global nanotechnology innovation were not considered specific to nanotechnology but, rather, generic to all high-tech fields [64]. Some of the examples presented include: the low levels of investment in emerging technologies [55]; the Northern concentration of proprietary knowledge [47] - with nanotechnology said to raise issues similar to those at the forefront of the biotechnology debate in this respect [39]; there were also shared problems in the hesitation of the private sector to engage in nanotechnology R\&D and difficulties associated with technology transfer [37].

If many of the challenges are generic, is there anything to suggest that global roles in emerging innovation will change at the hands of nanotechnology? Will this divide be any different to preceding technological divides? Selgelid thought not, saying he saw no reason why the general situation relating to inequality would be any different for nanotechnology:

The North-South divide is really complex and I do not see why there should be anything special or unique about the North-South divide or rich-poor divide as far as nanotechnology [is concerned]. I would imagine the same kind of dynamics that are driving inequality in all kinds of other domains would just apply to this domain, as well... [52]. 
Others were concerned that nanotechnology's innovation divide could be "exaggerated" [40] and worse than the divide currently witnessed with ICT [58]. This view was partially justified by a belief that nanotechnology enters a platform of existing and widening divides [37, 51,58], particularly those for biotechnology and ICT [47]. In this light, Yuthavong ${ }^{x i i i}$ saw potential for an extreme shifting of R\&D concentration away from developing countries, saying that nanotechnology R\&D is "moving too fast" for many developing countries to "... really capture the benefits fully" [49], with Sawanpanyalert adding that Northern countries are in a much more favourable position to respond and adapt their capabilities [37, 43, 47]. However, as shall be explored in section 2.3, others saw nanotechnology presenting new opportunities for the South to play an active role in global innovation.

\subsection{New Opportunities}

Whilst previous arguments suggest that an active role in nanotechnology innovation is beyond the South, others suggest that the barriers are more matters of perception [48, 60] and that nanotechnology can also be viewed as an opportunity for the South [49]. As noted in previous research, despite seemingly universal understandings, nanotechnology conjures a range of perceptions, some of which fail to consider nanotechnology in some of its more simple forms [7]. 'Further consideration' is suggested as leading to more 'circumspect' perspectives [37], with Selgelid's responses highlighting this point - after considering the issues in greater detail, Selgelid stated "...there is the possibility that nanotechnology is not out of the reach, or should not be out of the reach of developing countries" [52]. In this respect, a number of interviewees, particularly those from Thailand, saw alternative paths that involved the South as 'nano-innovators', actively contributing to nanotechnology's global trajectory. Nearly one-third of interviewees from both Australia and Thailand specifically referred to nanotechnology providing 'opportunities' or holding 'potential' for Southern innovation [37, 39-41, 46, 49, 59-61]. In fact, some even suggested that Southern countries actually "...have the advantage" in terms of nanotechnology innovation [48] and that, on the back of various technologies, the South would "be at the same level" as the developed countries at some future stage [60]. In this section I provide supporting arguments for many of these claims.

Two elements, each of which I will explore in this section, contribute to the argument that the South can play an active role in global nanotechnology innovation. The first element is that early signs of Southern nanotechnology commitment could set a platform for more active engagement in global innovation, including hope for engagement that includes some of the Least Developed Countries (LDCs). In this respect, interviewees also outlined constraints as to the kind of nanotechnology activity that might be possible. The second element is the suggestion that Southern countries

xiii Who, as of 2007, is Thailand's Minister of Science and Technology. 
might be able to overcome a number of the previously raised barriers and challenges to developing innovative capabilities.

Interviewees introduced the issue of Southern nanotechnology commitment by citing nine developing countries active in nanotechnology R\&D and commenting on the strength of each country's commitment. China was the one Southern country presented as a playing a most active role in nanotechnology and was often grouped with the North, given it is "...moving so fast and putting so many resources into nanotechnology..." [47]. Warris noted that "...China had the highest ratio [of nanoscience compared to their total science] in the world", highlighting that it had identified nanotechnology as an area of increasing importance [45]. Following China, India, South Korea and South Africa were all seen as playing highly active roles ahead of Thailand, Malaysia, Vietnam, the Philippines and Indonesia who were viewed as playing moderately active roles. Although Tegart saw the Phillipines, Vietnam and Indonesia as "much further behind" there was chance for strong presence from these three [37]. As Tanthapanitchakoon noted, there is a lot of enthusiasm in a country such as Vietnam where the government are "very keen to promote their nanotechnology program", in order to "catch up" [47].

Thailand provides an interesting case given it is a 'middle-range' developing country seeking to make its mark in global nanotechnology innovation. Both Tegart and Turney spoke about the willingness and drive from Thailand to harness nanotechnology through the development of innovative capabilities [37, 48]. Thai interviewees confirmed the strong desire and ambitions, with Pothsiri noting that the Thai government's policy is "...to promote this kind of innovation to be... something that we would be able to do by ourselves...." [66]. Arya said that the Thai government's hopes are actually targeted at ensuring nanotechnology contributes up to one per cent of the Thai Gross Domestic Product in the coming ten years [38]. Strategically, given its central location amongst South East Asian nations, Thailand is seeking to be a "hub" for nanotechnology [41], with Tegart positive that Thailand could be among the leaders in South East Asia if it receives strong government support [37].

Both interviewees and practitioners saw government support and 'endorsement' for nanotechnology as real strengths for Thailand. Pothsiri, speaking about the Thai nanotechnology climate said that "right now the chance is quite good [to build capacity] because there is a policy commitment from the government" [66]. Interviewees said that the policy commitment had already resulted in initial funding, with Damrongchai adding that there is enough money available to make a substantial investment in nanotechnology R\&D [39]. In addition to early funding, interviewees mentioned the establishment of a national nanotechnology centre and the earmarking of specific agencies to drive nanotechnology forward [66]. Interviewees also noted that this policy commitment was translating into support for nanotechnology across a number of sectors. Thajchayapong highlighted examples from his own experiences with the Ministries of Commerce and Defence: 
...two weeks ago, I was delighted that I was invited by [the] Ministry of Commerce Permanent Secretary and I was explaining to them about nanotechnology, in front of 150 or 200 people... [similarly, at] the military school, they had about 150 student[s] listening to nanotechnology... [62].

However, interviewees were quick to highlight that these developments all stemmed from the Thai Prime Minister who was pinpointed as the main driving force for nanotechnology in Thailand [39, 42, 63, 68]. Turney more explicitly noted that "the Prime Minister is actually driving this, personally, as something he wants to see happen" [48], with Tanthapanichakoon adding that the Prime Minister individually realised the importance of emerging technology, such as nanotechnology, for Thailand's future [47]. Thajyapong, highlighting the importance of political leadership in a country such as Thailand, outlined the circumstances in which the Prime Minister initiated Thailand's first serious foray into nanotechnology:

... about two years ago he [the Prime Minister] went to the science park. He visited us and he was surprised. He used the words to the effect, 'I did not realise that you have done so much' and then he mentioned about nanotechnology. And that is how we say, 'o.k., if Prime Minister use the word nanotechnology we have to respond' and we set up the centre [62].

Thailand's high level of commitment, combined with the previously mentioned nanotechnology activity in other countries, suggests the existence of foundations upon which Southern countries could play active roles in global nanotechnology innovation. A few of the Australian interviewees admitted surprise at the early nanotechnology capabilities in some of the developing and transitional countries $[37,54]$. BraachMyksvitis saw the "early start" from developing countries as something new in the science and technology arena [54]. In this respect, Cooper said that nano-innovation does not have to follow the same distributive pattern as biotechnology innovation, believing that early widespread engagement "...totally changes the picture" [56]. In presenting hopeful visions of Southern countries playing active roles in global nanotechnology innovation, some referred to other Southern successes such as the development of the Indian pharmaceutical industry in the 1970s that produced cheap drugs geared at local needs [56] and South Africa's recent ability to build a critical mass of scientific researchers [65].

Although the examples presented thus far mainly deal with the more advanced developing countries, there was a belief that the nanotechnology revolution could extend to the LDCs or 'very poor countries' [57,60]. Charinpanitkul, who assessed Thailand's nanotechnology capabilities in 2004, said that countries like Laos could be conducting nanotechnology research within 5 years [41].

However, interviewees also placed limitations on the scope and nature of nanotechnology activity that might be possible in some Southern countries.

In terms of scope, there was a belief that Southern countries might only be able to engage with nanotechnology innovation at certain stages of the R\&D cycle. Although Sawanpanyalert did not see Southern countries as necessarily able to work on 'early- 
stage' nanotechnology research, he said that there are opportunities for 'later research' [43]. In this respect, Southern innovation was seen as dependent on partnerships with the North [43, 48, 49], particularly in an area such as drug development where developing countries "cannot do it alone" and will require "assistance from developed countries" [49]. Dutta pointed to countries such as Switzerland and Sweden as partners for components of the R\&D phases that cannot be completed in Thailand [60].

However, Braach-Maksvytis, harking back to the way nanotechnology is perceived, noted that the scope of a country's contribution to global nanotechnology innovation "...depends on what end of the scale you are talking about" [54]. Low-tech scale production of nanopowders for cosmetics, plastics and the polishing of silicon chips could be globally widespread and developed entirely within the South [54], whilst "niche products for which you need very high investments" might remain outputs from the North [60].

In terms of the nature of nanotechnology research, the ability to conduct both fundamental and applied scientific research across all fields, was seen as beyond many of the Southern countries [38]. Arya explained this situation in greater detail, in the Thai context:

...Thailand is not in a good position to compete at the fundamental research level. We do not have the capacity, we do not have the potential. So, whereas we can do some fundamental research for nanomaterials or nanotechnology, we have to look, more, at the applied research. [38].

As shall be explored in a future paper, the need to focus on applied research was closely followed by a need for Southern countries to find their own niche areas of application, building on niche knowledge [38, 69].

As alluded to in section 2.2, a range of capacity issues contribute to determining a countries' level of engagement with nanotechnology [41, 43]. Nonetheless, arguments were made in six areas for why Southern countries might be able to overcome some of the previously raised barriers and challenges to developing innovative capabilities.

\subsubsection{Availability and Demand of Human Resources}

The first argument related to the level of available human resources to drive nanotechnology R\&D. With respect to the Thai situation, Tanthapanichakoon noted that, from the outset, the Prime Minister demanded particular effort in the area of "human resources development in nanotechnology" [47]. The general belief was that Thailand possesses an adequate workforce to commence nanotechnology $R \& D$ initiatives [39], with an estimated number of "not less than 100 researchers ${ }^{\mathrm{xiv}} \ldots$ [and]

\footnotetext{
xiv Thajchayapong draws this statistic from a 2003 study titled: "Final Report: Survey for Current Situation of Nanotechnology Researchers and R\&D in Thailand", that was conducted by the Unisearch group at Chulalongkorn University in Bangkok [12].
} 
nearly twenty laboratories that have been working on nanotechnology, scattered around [the] universities" [62].

These views are coupled with a belief that nanotechnology might not require a big labour force [44] - that a small number of scientists, with differing backgrounds but unified in their focus on nanotechnology "can be quite a big force" [49]. The implication is that countries could consider nanotechnology innovation even if they only had a few researchers in nanotechnology-related fields [45]. Lynksey, although previously sceptical about the hopes for endogenous innovation, said that getting a 'critical mass' is possible for countries that have a credible, political approach - even some of the LDCs, although this would be ".... ca couple of generations away" [65]. Yuthavong agreed, stating that Thailand can develop a critical mass of scientists "if it gets the right policy and right directives" [49].

Furthermore, discussing nanotechnology with some of the Thai interviewees unearthed a surprising number of people who claimed that they, or their colleagues, had been working in nanotechnology for many years. This was coupled with a belief that, in Thailand, a number of things have already been done on the nanoscale [69]. Charinpanitkul, who produced Thailand's first national assessment of nanotechnology capabilities, cited Thai quantum dot research before the 1990s and, more recently, carbon nanotube research from the late 1990s [41]. Surveyed practitioners claimed to have been working in nanotechnology for an average of 6.2 years, with some claiming as much as 14 years. To explain this, some interviewees referred to support for 'nanotechnology' as a recent Thai phenomenon:

...back 10 years or more... I was studying in that field [nanotechnology] and researching the molecular assembly of molecules... but at that time the environment in Thailand was not very supportive of doing research into nanotechnology... [39].

In this light, Damrongchai believed that Thailand has enough workers with the appropriate skills and experience to seriously engage in nanotechnology innovation [39]. Songsivilai added that the diverse backgrounds of the Thai scientific workforce are an advantage in terms of the skill-sets nanotechnology $R \& D$ requires [69]. In further support, my assessment of Thai practitioners who claimed to be working in nanotechnology showed a highly qualified workforce, with nearly all having completed doctorates. Kanok-Nukulchai said that within three to five years someone in Thailand will receive a Masters or PhD degree in nanotechnology [42]. In the broader context of Southern countries, Berwick suggested that "...[a] mastery of the basic principles of nanotechnology can be applied across the board..." [46].

\subsubsection{Infrastructure}

In addition to the hopes of addressing human resource barriers, interviewees suggested nanotechnology could bypass some of the infrastructural challenges commonly associated with many emerging technologies. Dutta suggested that developing 
bionanotechnology applications, for example, does not necessarily need an extensive biotechnology centre [60]. Similarly, Radt claimed that nanotechnology "could transform any developing country to catch up with the scientific communities [sic]" considering that, in an area such as drug development, it does not necessarily rely on "very expensive and long-lasting studies" [64].

Additionally, some interviewees challenged the belief that nanotechnology R\&D requires special instrumentation or world class facilities, claiming, rather, that many developing countries have much of the standard instrumentation that is needed [60, 64]. With these points in mind, Radt distinguished nanotechnology from the capital intensive nature of the previously emergent computer chip industry that needed "big clean rooms, big plant[s]... [and] a lot of extremely expensive instruments to start" [64].

Furthermore, interviewees believed that nanotechnology R\&D can utilise existing infrastructure and previous approaches "...because nanotechnology is based on the basic sciences: chemistry, biology and engineering..." [64]. With similar thoughts in mind, interviewees presented nanotechnology as a "natural progression" for Thailand, given its background in biotechnology research [43, 47]. Thus, interviewees often spoke of nanotechnology R\&D as merely a modification or "upgrading" of existing activities and infrastructure [66]. As Chirachanchai noted, "...what we have now, we can apply it but just change the point of view from 'trial and error' to understanding at the molecular level" [59]. Coyle suggested that, although "the terms may be new...", it is, in fact, putting into effect much existing knowledge, with a new emphasis on the way to do things [50]. In this respect, Chiranchanchai said it is actually more a matter of identifying people's roles and that the infrastructure will naturally develop when people come together [59].

\subsubsection{International Knowledge}

Building on the argument that nanotechnology can utilise existing infrastructure, interviewees presented a strong belief that developing countries can "leapfrog" their R\&D capabilities and position within global innovation [38, 45-47, 49, 54, 60, 64-66, 68]. When interviewees referred to 'leapfrogging', they spoke of utilising existing knowledge and research efforts by scientists in other countries, learning "...from what has already been done..." [46] in order to adapt and extend the lessons learnt [59]. Thai interviewees, in particular, saw opportunities for countries to "jumpstart" their R\&D activities [57], avoiding the need to start from "square one" [47, 57]. But BraachMaksvytis said that the potential for Southern countries to leapfrog in nanotechnology innovation also paves the way for a new trajectory, whereby countries could "steer a new, emerging science area into a very real and very practical outcome" [54]. BraachMaksvytis elaborated:

...rather than going down the track of implementing technologies and devices that developed countries have now and then just repeating that, to actually look beyond already and use the new worlds that new technologies open up 
[54].

The ability to leverage global nanotechnology developments was seen as a major positive for a country such as Thailand [37, 38, 45, 58]. Tanthapanichakoon expressed the Thai thinking that there is no need to "....reinvent the wheel... we want to know what the world has and what kinds of existing technologies we might make use of in order not to start from scratch" [47]. This is made all the more easy given, " .... lot of papers can get translated, [and] put on the Internet a lot quicker now..." [46]. Furthermore, there was a belief from Thai nanotechnology practitioners that, because nanotechnology is 'new' and not yet well defined, it is not too difficult to catch up, with Dutta adding that Thailand's 'late' start "does not necessarily mean that we have lost anything..." [60].

On the contrary, Kanok-Nuckulchai suggested that the very nature of backwardness means that 'falling behind' in nanotechnology may not be such a big issue for some countries "because they can wait until the leading country develop[s] these technologies and they can follow" [44]. In fact, in looking to leap ahead, the South's 'backwardness' in nanotechnology R\&D was even viewed as potentially advantageous in terms of saving "time and money" [60].

There was a general recognition that support and cooperation from the North can be useful in Southern efforts to 'catch up'. In this respect, Turney noted early signs of Northern support for Southern nanotechnology programs, highlighting the case of Japan that is currently “...funding educational programs within countries like Malaysia and Thailand" [48]. In this instance, Turney saw the net benefit as a flexible, highlyskilled workforce from which all countries can benefit [48].

\subsubsection{Research and Development Costs}

Whilst entry costs were previously raised as a barrier for Southern innovation, many saw nanotechnology offering "a door for countries into research even if they do not have as large funding bodies as perhaps highly developed countries" [64]. In addition to the benefits outlined in 5.3.1, 5.3.2 and 5.3.3, Ford said that there is considerable potential for Southern innovation "...for the simple reason that a lot of nanotechnology is extremely cheap"[61]. Some interviewees agreed that big budgets are not necessary to commence working in nanotechnology [59], as highlighted by the Thai situation where the initial budget of 6 million baht ${ }^{\mathrm{xv}}$ was "...enough, at that stage" [62].

However, it is important to note that low budgets do not necessarily equate to 'low-end' nanotechnology in terms of the sophistication of R\&D output. Rather, many nanotechnology approaches allow "...very useful and high-impact experiments with relatively small budgets..." [64]. For example, given it utilises natural chemical reactions, self-assembly was seen as a potentially inexpensive means by which the

\footnotetext{
${ }^{\mathrm{xv}}$ approximately equivalent to $\$ 165,000$.
} 
South could play an active role in cutting-edge nanotechnology innovation [59, 69]. As Radt noted with nanotechnology-based drug delivery systems:

...most of the nanotechnological systems are self-assembling systems, therefore, often it is possible to simply put reactants together in the right order... it is possible to produce these systems in parallel in a large scale... self assembling systems are easy to scale-up and that is why they are potentially useful and cheaper [64].

In addition to cost reductions for drug development arising from chemical selfassembly, Chirachanchai saw nanotherapeutics as potentially inexpensive because increased molecular understanding, combined with advances in simulation, would minimise the need for 'trial-and-error' research [59].

A number of these cost-cutting factors contributed to Dutta referring to what he termed "poor man's nanotechnology" [60], whereby nanotechnology could offer entry points to cater for all sorts of residual Southern capacity:

If I think about a country like Laos... it is lacking resources... I would suggest that, 'look I am doing nanotechnology the poor man's way'... I am using colloidal nanoparticles and trying to find out applications of each ones. Laos could possibly also concentrate on things like this [60].

\subsubsection{Comparative Advantage}

Low costs are also assisted by traditional and new means of comparative advantage. Advantages were said to revolve around traditionally proposed areas, such as the low costs of labour, easy access to clinical trial participants and natural resource abundance. However, a number of advantages were suggested as specifically relating to nanotechnology. Thai nanotechnology practitioners directly referred to their nanotechnology research utilising local biological products and raw materials, such as herbal products with natural resource bases [41, 47]. According to one practitioner, the link to resources also included the ability to produce nanomaterials from local materials. This was seen as a potential cost-saving advantage for a country like Thailand, with Chiranchanchai suggesting that if Thailand produces a nanoscale product, such as a base for drug delivery, "...the products, compared to other countries, may be cheap if we use our natural abundance for that" [59].

\subsubsection{Private Sector Support}

In terms of some of the capacity matters raised in section 2.2, Damrongchai challenged the belief that researcher retention would be an issue for a country such as Thailand, saying that there are enough researchers who would want to remain in Thailand [39]. There was also a belief that the early signs in Thailand suggest adequate private sector support for nanotechnology. According to some, industry is showing early interest in nanotechnology [41, 62], signalling a positive change in perceptions amongst Thai 
businesses that now see it as a "promising field" [41] that is resulting in the emergence of nanotechnology entrepreneurs [48].

In this light, although Tanthapanichakoon agreed that Thailand faced technology transfer challenges and did not have any industrial products ${ }^{\mathrm{xvi}}$, he noted that some product samples and prototypes are being produced in labs [47]. Tanthapanichakoon added that the commercialisation stage of mass production was probably another two to three years away [47].

\section{Conclusion}

My initial research shows the existence of two, slightly different 'nano-divides'. The 'nano-innovation divide' relates to where nanotechnology knowledge is generated and retained, whilst the 'nano-orientation divide' relates to where nanotechnology research is targeted. The nano-innovation divide is the platform on which the nano-orientation divide is determined. Early levels of nanotechnology funding in the North appear to be driving the innovation divide, which is framed in the absolute terms of: countries that lead R\&D and those that are 'left behind'. In this sense, the nano-innovation divide was negatively viewed, with no one raising the possibility that the divide might be a good thing, either for the world in terms of maintaining an effective international division of labor or, perhaps more importantly, for a country in terms of it entirely averting engagement with nano-innovation. This suggests an immediate mainstreaming of nanotechnology debates into a competitive, nationalistic 'growth' narrative that leaves little space for post-development critiques or notions of alternative trajectories.

In terms of new possibilities for Southern dependency, fears were held for an increasing concentration of proprietary knowledge in the North, reinforcing and inequitable intellectual property regimen and accelerating the global division of labour. Compounding these issues are the proposed capacity challenges facing a country's efforts to develop endogenous nanotechnology capabilities. Although most of these challenges do not appear exclusive to nanotechnology, some key informants perceive them as inhibitive for Southern engagement in global innovation.

However, it would appear likely that nanotechnology also creates new potential for Southern innovation. There was a strong belief that nanotechnology innovation is misperceived as being beyond the capacity of developing countries. This was supported by reference to the early levels of Southern nanotechnology awareness and commitment, and subsequently raised the possibility that Least Developed Countries could become active in global nanotechnology innovation. However, interviewees noted that the possibilities were constrained in terms of the scope and nature of

\footnotetext{
${ }^{x v i}$ Although Panitchpakdi claimed Thailand has already produced a nanoscale diagnostic kit [55].
} 
nanotechnology activity that might be possible in some Southern countries. In particular, there are significant differences in potential 'scale'; from those countries' where nanotechnology innovation might occur on a relatively small scale and be targeted towards a certain phase in the R\&D process, to those for whom the scale of nanotechnology innovation is more broadly encompassing and comparable to $R \& D$ efforts in the North. Although some are generic, most of the factors raised in arguments supporting the ability for Southern countries to engage in nanotechnology innovation relate specifically to nanotechnology.

Overall, Australian interviewees were more likely to consider Southern nanotechnology within a global context of external challenges to building endogenous capacity, identifying market-dictated challenges, such as the orientation of nanotechnology research and development, its cost and its availability, as well as other structural barriers relating to the global patent system. From this perspective, the development 'problem' is seen to include global institutions in the North, implying that any positive, sustainable alteration of the divides' trajectory must address international imbalances in systems of trade as well as other structural inequalities.

Thai interviewees were more likely to consider nanotechnology within a domestic context of internal challenges to building endogenous capacity. They identified capacity issues such as developing adequate human resources and technical infrastructure, as well as ensuring political support and appropriate financing. From this perspective, the development 'problem' is seen more as a result of Southern inabilities, with Southern countries viewed as 'backward' or 'lagging' and needing to 'catch-up'.

My research has reinforced the critical influence of how nanotechnology is perceived in terms of debates on how it will unfold. Building on the findings of previous research [7], interviewees commonly made arguments based on fluid definitions for nanotechnology and the possibilities it raises. This point explains a number of apparent contradictions, particularly in areas such as nanotechnology's infrastructural and cost requirements, where interviewees presented an unusually wide range of views. The conflicting views also raise the interesting question as to the role of hype in nanotechnology discourse.

Equity is a central ethical issue in the international debates around nanotechnology. However, current thinking, as supported by this research, suggests that greater equity can only occur on a platform of more widespread nano-innovation, where nations become more globally competitive. Ultimately, this thinking limits subsequent debates to a narrative underpinned by the contested philosophies of 'sustainable economic development' and denies the many, creative alternatives emerging worldwide.

\section{Acknowledgment}


This paper was presented at the Third Nano Ethics Workshop held at the University of Aarhus, October, 2008. The author is grateful to the Nano Ethics Network for their support in making this presentation possible.

\section{References}

[1] F.N. Moore, Implications of Nanotechnology Applications: Using Genetics as a Lesson. Health Law Review, 2002. 10 (3): 9-15.

[2] M.D. Mehta, Nanoscience and Nanotechnology: Assessing the Nature of Innovation in These Fields. Bulletin of Science, Technology \& Society, 2002.22 (4): 269-273.

[3] M. van Amerom and M. Ruivenkamp, Image Dynamics in Nanotechnology's Risk Debate. in Second International Seville Seminar on Future-Oriented Technology Analysis: Impact of FTA Approaches on Policy and Decision-Making. 2006. Seville, Spain.

[4] M.H.A. Hassan, Nanotechnology: Small Things and Big Changes in the Developing World. Science, 2005. 309 (5731): 65 - 66.

[5] E. Court, A.S. Daar, E. Martin, T. Acharya, and P.A. Singer, Will Prince Charles Et Al Diminish the Opportunities of Developing Countries in Nanotechnology? 2004, (February 2004) [cited Available from: http://www.nanotechweb.org/articles/society/3/1/1/1

[6] D.C. Maclurcan, Nanotechnology and Developing Countries: Part 2 - What Realities. AzoNano Online Journal of Nanotechnology, 2005, [cited October 30, 2005]. Available from: http://www.azonano.com/Details.asp?ArticleID=1429.

[7] D.C. Maclurcan, Nanotechnology and the Global South: Exploratory views on characteristics, perceptions and paradigms, in Nanotechnology policy: society, ethics, and public engagement (in press), S. Arnaldi, A. Lorenzet, and F. Russo (Eds). 2009, IOS Press, Amsterdam.

[8] O. Gutierrez, Experimental techniques for information requirements analysis. Information and Management, 1989. 16 (1): 31-43.

[9] W. Mee, R. Lovel, F. Solomon, A. Kearnes, and F. Cameron, Nanotechnology: The Bendigo Workshop Report. 2004, Melbourne: CSIRO Minerals. CSIRO Minerals. pp. 30.

[10] N. Invernizzi and G. Foladori, Nanotechnology and the Developing World: Will Nanotechnology Overcome Poverty or Widen Disparities? Nanotechnology Law and Business Journal, 2005. 2 (3): 101-110.

[11] D. Loveridge, Experts and Foresight: Review and experience. Discussion Paper Series. 2002, Manchester: The University of Manchester. The University of Manchester. pp. 37.

[12] Unisearch, Final Report: Survey for Current Situation of Nanotechnology Researchers and R\&D in Thailand. 2004, Bangkok: Chulalongkorn University. Chulalongkorn University. pp. 42.

[13] United Nations Development Program, Thailand Human Development Report 2007: Sufficiency Economy and Human Development. 2007, Bangkok: United Nations Development Program. United Nations Development Program. pp. 152.

[14] United Nations Development Program, Human Development Report 2003: Millennium Development Goals: A Compact Among Nations to End Human Poverty. 2003, New York: Oxford University Press. Oxford University Press. pp. 367.

[15] World Bank Independent Evaluation Group, Development Results in Middle-Income Countries: An Evaluation of the World Bank's Support. 2007, Washington, D.C.: The World Bank Group. The World Bank Group. pp. 162.

[16] S. Sahai, Biotechnology Capacity of LDCs in the Asian Pacific Rim. AgBioForum, 1999. 2 (3\&4): 189-197.

[17] L. Liu, Current Status of Nanotech in Thailand. Asia Pacific Nanotechnology Weekly, 2003.1 (19): 1-4.

[18] P. Thajchayapong and W. Tanthapanichakoon, Current Status of Nanotechnology Research in Thailand. in Nano tech $2003+$ Future (International Congress and Exhibition on Nanotechnology). 2003. Tokyo, Japan: New Energy and Industrial Technology Development Organization.

[19] W. Tanthapanichakoon, An Overview of Nanotechnology in Thailand. KONA, 2005, (23): 64-68

[20] S. Panyakeow and P. Aungkavattana, Nanotechnology Status in Thailand, in Nanotechnology the Technology for the 21st Century: Vol. II The Full Report, G. Tegart (Ed). 2002, APEC Center for Technology Foresight, Bangkok. pp. 163-168. 
[21] J. Lin-Liu, Thailand's Leader Plants the Seeds for a Future in Nanobiotech. Small Times, 2003, [cited June 11, 2004]. Available from: www.smalltimes.com/document display.cfm?document id=5588.

[22] P. Sutharoj, Nanotechnology: Ten-year plan for Asean leadership. The Nation, 2005, [cited June 30, 2005]. Available from: http://www.nationmultimedia.com/2005/06/27/byteline/index.php?news=byteline 17840267.html

[23] A. Sandhu, Thailand resorts to nanotech. Nature Nanotechnology, 2008. 3 (8): 450-451.

[24] T. Changthavorn, Bioethics of IPRs: What does a Thai Buddhist think? in Roundtable discussion on Bioethical Issues of IPRs. 2003. Selwyn College, University of Cambridge.

[25] C. Kachonpadungkitti and D.R.J. Macer, Attitudes to Bioethics and Biotechnology in Thailand (1993-2000), and Impacts on Employment. Eubios Journal of Asian and International Bioethics, 2004. 14 (2004): 118-134.

[26] W.A. Kerr, J.E. Hobbs, and R. Yampoin, Intellectual Property Protection, Biotechnology, And Developing Countries: Will The TRIPs Be Effective? AgBioForum, 1991. 2 (3\&4): 203-211.

[27] R. Meléndez-Ortiz and V. Sánchez, (Eds) Trading in Genes: Development Perspectives on Biotechnology, Trade, and Sustainability. 2005, Earthscan: London.

[28] Knowledge Ecology International, Thailand's Compulsory Licensing Controversy [cited September 19, 2008]; Available from:

http://www.keionline.org/index.php?option=com content\&task=view\&id=90.

[29] ETC Group, Scientists Prepare to Use Nanotechnology to Poison Us All? - Jazzing up Jasmine: Atomically Modified Rice in Asia? News Release, 2004, [cited April 4, 2004]. Available from: www.etcgroup.org/en/materials/publications.html?pub id=117.

[30] B.A. Cornell, V.L.B. Braach-Maksvytis, L.G. King, P.D.J. Osman, B. Raguse, L. Wieczorek, and R.J. Pace, A biosensor that uses ion-channel switches. Nature, 1997. 387 (6633): 580-583.

[31] C. Warris, Nanotechnology Benchmarking Project. 2004, Canberra: Australian Academy of Science. Australian Academy of Science. pp. 45.

[32] B.G. Priestly, A.J. Harford, and M.R. Sim, Nanotechnology: a promising new technology — but how safe? Medical Journal of Australia, 2007. 186 (4): 187-188.

[33] D. Bowman and G. Hodge, Nanotechnology and Public Interest Dialogue: Some International Observations. Bulletin of Science, Technology \& Society, 2007. 27 (2): 118-132.

[34] N. Britten, Qualitative Research: Qualitative interviews in medical research. British Medical Journal, 1995. 311 (6999): 251-253.

[35] M.J. Garrett, health futures: a handbook for health professionals. 1999, Geneva: World Health Organisation. pp. 320.

[36] A. Reid, L.N. Wood, G.H. Smith, and P. Petocz, Intention, Approach and Outcome: University Mathematics Student's Conceptions of Learning Mathematics. International Journal of Science and Mathematics Education, 2005. 3 (4): 567-584.

[37] G. Tegart, Interview by author. Tape recording. Canberra, Australia, 23 March 2004.

[38] G. Arya, Interview by author. Tape recording. Bangkok, Thailand, 10 August 2004.

[39] N. Damrongchai, Interview by author. Tape recording. Bangkok, Thailand, 28 July 2004.

[40] P. Deutchmann, Interview by author. Tape recording. Melbourne, Australia, 16 July 2004.

[41] T. Charinpanitkul, Interview by author. Tape recording. Bangkok, Thailand, 6 August 2004.

[42] W. Kanok-Nukulchai, Interview by author. Tape recording. Bangkok, Thailand, 8 August 2004.

[43] P. Sawanpanyalert, Interview by author. Tape recording. Bangkok, Thailand, 23 July 2004.

[44] W. Kano-Nukulchai, Interview by author. Tape recording. Bangkok, Thailand, 8 August 2004.

[45] C. Warris, Interview by author. Tape recording. Canberra, Australia, 6 July 2004.

[46] L. Berwick, Interview by author. Tape recording. Canberra, Australia, 6 July 2004.

[47] W. Tanthapanichakoon, Interview by author. Tape recording. Bangkok, Thailand, 22 July 2004.

[48] T. Turney, Interview by author. Tape recording. Melbourne, Australia, 16 July 2004.

[49] Y. Yuthavong, Interview by author. Tape recording. Bangkok, Thailand, 28 July 2004.

[50] P. Coyle, Interview by author. Tape recording. Sydney, Australia, 21 May 2004.

[51] B.A. Cornell, Interview by author. Tape recording. Sydney, Australia, 16 June 2004.

[52] M. Selgelid, Interview by author. Tape recording. Sydney, Australia, 7 May 2004.

[53] P. Bryce, Interview by author. Tape recording. Sydney, Australia, 20 May 2004.

[54] V.L.B. Braach-Maksvytis, Interview by author. Tape recording. Melbourne, Australia, 5 April 2004.

[55] P. Panitchpakdi, Interview by author. Tape recording. Bangkok, Thailand, 10 August 2004.

[56] M. Cooper, Interview by author. Tape recording. Sydney, Australia, April 302004.

[57] P. Ratanakul, Interview by author. Tape recording. Bangkok, Thailand, 30 July 2004.

[58] J. Weckert, Interview by author. Tape recording. Canberra, Australia, 28 May 2004. 
[59] S. Chirachanchai, Interview by author. Tape recording. Bangkok, Thailand, 6 August 2004.

[60] J. Dutta, Interview by author. Tape recording. Bangkok, Thailand, 7 August 2004.

[61] M.J. Ford, Interview by author. Tape recording. Sydney, Australia, 9 July 2004.

[62] P. Thajchayapong, Interview by author. Tape recording. Bangkok, Thailand, 12 August 2004.

[63] N. Sriyabhaya, Interview by author. Tape recording. Bangkok, Thailand, July 232004.

[64] B. Radt, Interview by author. Tape recording. Melbourne, Australia, 16 July 2004.

[65] M. Lynskey, Interview by author. Tape recording. Sydney, Australia, 27 May 2004.

[66] P. Pothsiri, Interview by author. Tape recording. Bangkok, Thailand, 10 August 2004

[67] UNCTAD, Process Patents: Burden of Proof. CY564-Unctad, 2004. 1 (November 29): 496.

[68] T. Changthavorn, Interview by author. Tape recording. Bangkok, Thailand, 11 August 2004.

[69] S. Songsivilai, Interview by author. Tape recording. Bangkok, Thailand, 11 August 2004. 